\title{
Strategi Personal Branding Perupa Melalui Media Sosial
}

\author{
Rusdi Hendra \\ Institut Seni Indonesia Padang Panjang \\ Jalan Bahder Johan, Guguk Malintang, Padang Panjang Timur, \\ Kota Padang Panjang, Sumatera Barat 27118 \\ E-mail: rusdihendra1993@yahoo.com
}

\begin{abstract}
ABSTRAK
Perkembangan teknologi informasi dan media jejaring sosial saat ini menyebabkan pembentukan personal brand melalui media sosial semakin penting. Masyarakat Indonesia dikenal sebagai pengguna aktif media sosial. Menjadi seorang perupa harus memiliki keunikan tersendiri untuk dapat berbeda dengan perupa lainnya. Dalam membangunnya, dibutuhkan personal branding yang baik untuk dapat maju dan berkembang di dalam dunia seni rupa. Piko dengan akun @iabadioupiko telah melakukannya lewat media Instagram. Personal branding yang dilakukan Piko menarik dengan mengunggah hasil karyanya untuk menarik perhatian galeri dan menggunakan Instagram sebagai alat penyampaian pesan komunikasinya. Penelitian ini menggunakan metode deskriptif kualitatif dengan teknik pengumpulan data yaitu wawancara dan melakukan observasi terhadap dokumentasi yang dimiliki dan melakukan tinjauan literatur. Data yang didapat kemudian dianalisis menggunakan teknik analisis yaitu mengorganisasikan data, mereduksi data, peringkasan, dan penyajian data. Hasil akhir dari analisis data dapat mengetahui tentang bagaimana strategi personal branding perupa melalui media sosial Instagram dengan indikator yang terdiri dari kesebelas karakteristik authentic personal branding oleh Rampersad. Hasil penelitian menyebutkan bahwa strategi personal branding Piko ialah memiliki nilai, karakter, kode perilaku, berfokus pada satu bidang, konsisten, memiliki relevansi, memiliki visibilitas, mendapatkan pengakuan, menerapkan hal positif, serta menjadi diri sendiri dengan tetap menjaga eksistensinya dan selalu memelihara hubungan yang terjalin baik dalam akun Instagram @iabadioupiko maupun dalam kesehariannya.
\end{abstract}

Kata kunci: personal branding, media sosial Instagram, perupa, strategi

\section{The Artist's Personal Branding Strategy Through Social Media ABSTRACT}

The development of information technology and social networking media has made personal brands' formation through social media increasingly important. Indonesian people are known as active users of social media. Being an artist must be unique to be different from other artists. In building it, good personal branding is needed to advance and develop in the world of fine arts. Piko, with the @iabadioupiko account, has done this via Instagram. Piko's personal branding is impressive by uploading his work to attract the attention of galleries and using Instagram to convey his communication messages. This study used a qualitative descriptive method with data collection techniques, namely interviews and observing documentation, and conducting literature reviews. The data obtained were then analyzed using analytical techniques, namely organizing data, reducing data, summarizing, and presenting data. The final result of the data analysis can find out about the personal branding strategy of the artists through social media Instagram with indicators consisting of eleven characteristics of authentic personal branding by Rampersad. The results show that Piko's personal branding strategy is to have values, character, code of behavior, focus 
on one area, be consistent, have relevance, have visibility, gain recognition, apply positive things, and be yourself while maintaining its existence and always maintaining good relationships. They were established both in the Instagram account @ iabadioupiko and in his daily life.

Keywords: personal branding, social media Instagram, artists, strategy

\section{PENDAHULUAN}

Pada saat ini penggunaan sosial media sebagai sarana informasi dan komunikasi sudah menjadi hal yang utama bagi manusia dan masyarakat Indonesia dikenal sebagai pengguna aktif media sosial. Media sosial membuka peluang besar bagi pembentukan personal branding yang dapat memberikan dampak positif bagi perkembangan profesi. Personal branding tidak hanya terjadi di dalam ruang dan waktu nyata tetapi juga terjadi di dalam ruang representasi virtual seperti media sosial, namun penggunaan media sosial saat ini belum banyak secara sadar digunakan untuk personal branding bagi perupa. Personal branding adalah proses membawa skill, kepribadian, dan karakter untuk seseorang untuk kemudian dapat membungkusnya menjadi sebuah identitas yang memiliki kekuataan lebih dibandingkan dengan yang lain.

Terbukanya jalur komunikasi secara aktif di media sosial dengan fitur-fitur yang dapat menampilkan identitas, data diri, dan aktivitas melalui foto dan video. Ini merupakan peluang terbuka yang harus dimanfaatkan dengan sebaik-baiknya untuk mengembangkan brand insan kreatif di Indonesia. Salah satunya perupa muda yang bergelut dengan dunia seni rupa, yang mana perupa muda ini memerlukan sebuah media untuk menampilkan eksistensi dan aktivitas dirinya sebagai perupa dengan menggunakan media sosial. Seorang perupa yang memiliki akun media sosial dan menampilkan hal-hal yang berkaitan dengan aktivitas dan ketertarikannya pada hal tertentu, seperti menampilkan hasil karya yang baru diciptakan atau menampilkan sebuah proses penciptaan karya itu sendiri, dan membuka peluang orang untuk merespons dan berinteraksi.

Semakin banyak interaksi dengan pemilik akun lain melalui karya yang ia tampilkan maka, perupa ini akan semakin dikenali oleh banyak orang dengan karakternya yang khas, dan citra diri dengan keunikan hasil karyanya akan terbentuk. Selain itu, media sosial dapat juga sebagai media promosi untuk memperkenalkan karyanya pada penikmat seni, galeri, kurator, kolektor, kritikus, jurnalis, art dealer, dan art management. Salah satunya perupa yang memanfaatkan sosial media Instagram-nya yaitu Iabadioupiko dengan akun Instagram @iabadioupiko. Pada tahun 2020 ini di dalam akun Instagram-nya sudah ada sekitar 1,942 unggahan dengan 9,531 pengikut, di mana pada Instagram tersebut berisi foto-foto hasil karyanya, ataupun potongan video proses dalam berkarya 
termasuk foto-foto/dokumentasi saat pameran di dalam negeri maupun di luar negeri.

Karena media sosial memberikan dampak positif bagi profesi sebagai perupa maka, penelitian ini membahas tentang bagaimana strategi personal branding perupa melalui media sosial Instagram. Teori utama yang digunakan peneliti dalam penelitian ini adalah teori personal branding yang berisikan sebelas karakteristik personal branding, sebagai berikut: (1) authenticity (keaslian), (2) integrity (integritas), (3) consistency (konsisten), (4) specialization (spesialisasi), (5) authority (wibawa), (6) distinctiveness (kekhasan), (7) relevant (relevan), (8) visibility (visibilitas), (9) persistence (kegigihan), (10) goodwill (kebaikan), (11) performance (kinerja) (Rampersad, 2008).

\section{METODE PENELITIAN}

\section{A. Metode Penelitian}

Metode yang digunakan dalam penelitian ini adalah deskriptif kualitatif. Rakhmat (2009) menyatakan bahwa penelitian deskriptif ditujukan untuk: 1) mengumpulkan informasi aktual secara rinci yang melukiskan gejala yang ada; 2) mengidentifikasi masalah atau memeriksa kondisi dan praktik-praktik yang berlaku; 3) membuat perbandingan atau evaluasi; 4) menentukan apa yang dilakukan orang lain dalam menghadapi masalah yang sama dan belajar dari pengalaman mereka untuk menetapkan rencana dan keputusan pada waktu yang akan datang.

Penelitian kualitatif adalah penelitian yang bermaksud untuk memahami fenomena tentang apa yang dialami oleh subjek penelitian (Moleong, 2012). Menurut Setianti, dkk. (2016), pendekatan kualitatif sebagai prosedur penelitian yang menghasilkan data deskriptif berupa kata-kata tertulis ataupun lisan dari orang-orang dan perilaku yang dapat diamati. Penelitian yang diangkat oleh penulis bersifat sosial sehingga penulis memilih metode deskriptif kualitatif dengan tujuan untuk meneliti objek secara mendalam dan untuk lebih dapat memahami tentang hal-hal yang berkaitan dengan latar belakang subjek penelitian.

\section{B. Lingkup Penelitian}

1. Lokasi Penelitian

Lokasi Penelitian adalah tempat di mana penulis melakukan penelitian, lokasi penelitian beralamat di Keloran, Tirtonirmolo, Kasihan, Bantul, Yogyakarta.

2. Objek Penelitian

Strategi personal branding perupa melalui media sosial.

3. Subjek Penelitian

Subjek penelitian yang dipilih merupakan key person atau orang kunci ahli yaitu seniman. Penentuan subjek dilakukan secara sengaja berdasarkan tingkat 
kepentingan, pengetahuan, serta pengalamannya sebagai seniman. Informan penelitian ini adalah seniman dengan nama Iabadiopiko dengan akun Instagram @iabadioupiko.

\section{Teknik Pengumpulan Data}

Pengumpulan data dilakukan dengan wawancara dan melakukan observasi terhadap dokumentasi yang dimiliki dan melakukan tinjauan literatur untuk mendukung hasil penelitian.

\section{Teknik Analisis Data}

Analisis data dalam penelitian kualitatif dimulai dengan menyiapkan dan mengorganisasikan data (yaitu data teks seperti transkrip data atau gambar seperti foto), untuk dianalisis, kemudian mereduksi data tersebut menjadi tema melalui proses pengodean dan peringkasan kode, dan terakhir menyajikan data dalam bentuk bagan, tabel, atau pembahasan (Cresswell, 2013: 251). Dalam penelitian ini, analisis data merujuk teori Cresswell. Adapun langkah-langkah analisis data yang digunakan terdiri atas empat hal, yaitu:

1. Mengorganisasikan data

Hasil wawancara ditranskrip secara manual menggunakan alat yang sederhana. Data rekaman wawancara dipindahkan di laptop dengan format mp3, dan penulis mendengarkan rekaman sambil menulis apa yang dikatakan dalam rekaman.

2. Reduksi

Langkah selanjutnya adalah mereduksi data dengan melakukan pengodean. Seluruh transkrip dikumpulkan menjadi satu dan dipilih sesuai dengan kode-kode yang sudah ditentukan berdasarkan sebelas karakteristik personal branding.

\section{Peringkasan}

Kode-kode yang telah ditentukan direduksi kembali agar lebih sederhana dan ringkas menjadi kata-kata yang dapat menggambarkan masing-masing pengertian indikator yang disimpulkan dari hasil wawancara.

\section{Penyajian data}

Pada tahap akhir dari penelitian ini, para peneliti menyajikan data, yaitu mengemas apa yang ditemukan dalam bentuk teks, tabel, bagan atau gambar (Crasswell, 2013: 261). Pada penelitian ini, penulis memvisualisasikan data dalam bentuk teks.

\section{HASIL DAN PEMBAHASAN}

Iabadioupiko adalah seorang perupa yang berasal dari Sumatera Selatan yang bertempat lahir di Prabumulih, Sumatera Selatan pada tahun 1984. Ia telah 
menyelesaikan jenjang kuliahnya di Akademi Desain Visi Yogyakarta (saat ini telah berganti nama Sekolah Tinggi Seni Rupa dan Desain Visi Indonesia (STSRD Visi) Yogyakarta). Saat ini Iabadioupiko menetap dan berkarya di Yogyakarta. Iabadioupiko aktif berpameran tunggal ataupun bersama dalam berbagai event seni rupa di antaranya pameran di Yogyakarta, Jakarta, Singapura, Malaysia, Itali, dan Cina, serta pernah meraih penghargaan di antaranya Finalis Bienal Indonesia Art Award, Finalis Dies Natalis ISI Yogyakarta, dan Finalis Pratisara Affandi Adikarya. Iabadioupiko juga aktif dalam sosial media Instagram dengan nama akun @iabadioupiko.

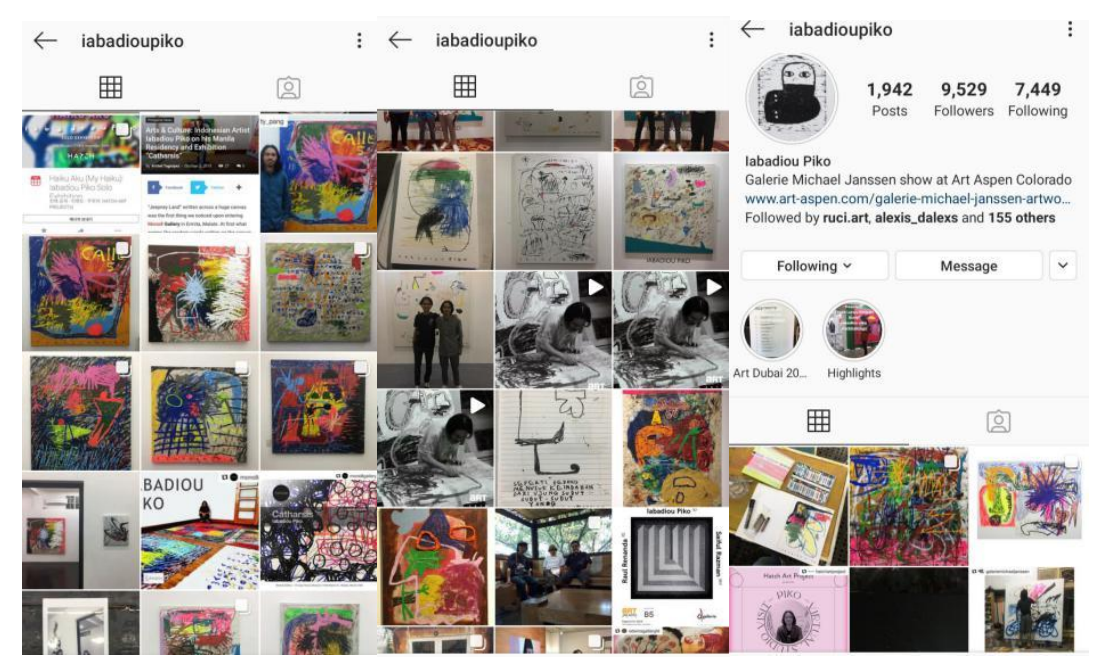

Gambar 1. Screenshot halaman Instagram Iabadioupiko

Sumber: Instagram @iabadioupiko, 2020

Strategi personal branding perupa ini didahului dengan pemenuhan terhadap kriteria personal brand yang dibutuhkan seseorang untuk dapat melakukan personal branding. Kriteria yang digunakan oleh penulis dalam penelitian ini adalah kriteria yang dikemukakan oleh Rampersad (2008). Dalam membangun personal branding melalui media Instagram sebagai seorang perupa, perupa menggunakan fitur visual yang diunggulkan Instagram dalam menyampaikan pesan personal branding yang dibentuk.

Konten-konten yang diunggah ke dalam akun Instagram pun haruslah memiliki keselarasan dengan ambisi pribadi yang dimiliki. Menurut Nugraha, dkk (2017), pada dasarnya penetapan branding dapat memberikan kelebihan branding suatu produk dan jasa. Nilai yang dibentuk oleh Piko dalam menjadi seorang perupa adalah sebagai seorang pelukis yang mempunyai prestasi. Prestasi yang dimaksudkan oleh Piko adalah prestasi di mana kontennya memiliki kegiatan yang merepresentasikan bagaimana prestasi dirinya dalam profesi yang ditekuninya. Karakter yang dibentuk Piko membentuk personal branding dirinya sebagai seorang perupa yang semangat dan simpel, tidak memiliki sifat yang rumit, dan 
terkesan santai. Hal ini sesuai dengan konten yang diunggahnya ke dalam akun @iabadioupiko yang lebih mengutamakan sisi artistik pada setiap kontennya. Ambisi pribadi yang Piko terapkan pun memiliki keselarasan dengan karakter yang dibentuk, karena keseharian yang dijalaninya sesuai dengan karakter yang diaplikasikannya. Berdasarkan karakteristik yang terdapat dalam Rampersad (2008), penulis dapat menyimpulkan bahwa Piko telah memenuhi beberapa poin dalam authenticity (keaslian).

Intergritas dalam Rampersad (2008) adalah mematuhi kode moral dan perilaku yang ditetapkan oleh ambisi pribadi. Dalam membentuk dan membangun personal branding yang otentik, taat kepada kode moral, dan perilaku yang telah ditetapkan oleh ambisi pribadi adalah kunci utama dalam menciptakan personal branding yang dapat dipandang baik oleh khalayak. Perilaku yang telah dibentuk oleh Piko sebagai seorang yang simpel dan semangat, terlihat pada konten Instagram-nya yang juga simpel dan teratur dengan tetap memperhatikan komposisi konten yang tidak mencerminkan pribadi yang negatif, dan selalu melakukan penyaringan terhadap konten yang akan diunggah pada akun @iabadioupiko agar konten selalu layak di benak khalayak/pengikutnya. Hal ini menurut penulis telah sesuai dengan konsep yang ada, karena dalam membentuk sebuah personal branding yang otentik haruslah didasarkan pada aturan yang telah ditetapkan oleh pribadi, dan integrity telah diterapkan Piko dalam akun Instagramnya.

Konsisten dalam buku Authentic Personal Branding (Rampersad, 2008) menyebutkan bahwa Anda harus konsisten dalam berperilaku. Kekonsistenan yang diterapkan oleh Piko dalam akun Instagram-nya dapat dikatakan telah memenuhi kriteria dan terlihat pada akun @iabadioupiko, Piko membentuk pola yang serupa, baik pada pekerjaannya, kesehariannya, ataupun relasinya. Konten yang disajikan sangatlah tertata pada satu konten dengan konten yang lainnya. Dalam mengunggah konten ke dalam akunnya, Piko konsisten untuk tetap mengunggah konten fotonya yang tidak memiliki pandangan negatif. Dalam kaitannya pada akun Instagram @ iabadioupiko, menurut pengamatan penulis, hal ini pun terlihat dari bagaimana setiap konten yang terdapat pada akunnya memiliki pola, dilakukan seragam dan berulang, baik pada sisi aktivitas, karya, maupun relationship sebagai seorang perupa. Hal tersebut dapat dikatakan konsisten karena penerapan yang terjadi dalam akun@iabadioupiko telah mencerminkan kekonsistenan Piko dalam mengatur feed-nya untuk membentuk benak khalayak. Dapat disimpulkan bahwa Piko telah konsisten dengan konsep yang telah ditetapkannya.

Specialization pada akun @iabadioupiko adalah, Piko mencondongkan akun dan dirinya ke dalam bidang lukisan abstrak. Hal ini dapat dilihat dari konten foto dalam akun Instagram @ iabadioupiko yang sering mengunggah foto karyanya saat pameran maupun sedang berkarya di studionya. Penulis menyimpulkan bahwa 
Piko memfokuskan dirinya ke dalam bagian pelukis abstrak. Hal ini terlihat dalam akun yang kembali mengunggah fotonya yang turut menekankan dirinya bahwa Instagram @iabadioupiko berkonsentrasi pada bidang lukis. Unggahan foto Piko dalam akun@iabadioupiko turut menegaskan bahwa dirinya memiliki spesialisasi bidang dan keterampilan yang ditekuninya, yaitu seorang pelukis.

Authority pada akun @iabadioupiko adalah Piko dalam penerapan personal branding dirinya, turut diakui oleh orang lain yang bekerja dengan dirinya, yaitu bidang lukis dengan tampilan abstrak. Pengalaman yang dimilikipun cukup banyak dalam pengamatan penulis, terlihat dari konten Instagram @iabadioupiko, bahwa dirinya telah mengikuti banyak pameran bersama serta pameran tunggal, baik di dalam negeri atau di luar negeri, yang semuanya turut diunggah ke dalam akun miliknya. Menjadi seorang pelukis pun, Piko turut selektif akan setiap tawaran pameran yang ditawarkan pada dirinya.

Distinctiveness dalam buku Rampersad (2008) bermakna bedakan diri berdasarkan merek Anda. Personal brand Anda perlu diungkapkan dengan cara yang unik dan berbeda dari kompetisi dan kebutuhan guna menambah nilai bagi orang lain. Personal branding perlu didefinisikan dengan jelas agar orang lain dapat dengan cepat memahaminya. Berdasarkan pengamatan dan penelitian yang penulis lakukan, Piko menekankan dirinya untuk condong menjadi seorang pelukis yang berkompeten di bidangnya yang memiliki kekhasan sendiri dalam karya lukisnya.

Relevant Personal branding yang sedang dibangun haruslah terhubung dengan yang dianggap penting oleh target audiens (Rampersad, 2008). Pada akun Instagram@iabadioupiko, Piko selalu mengunggah seluruh hasil kerjanya, baik dalam kerja, hubungannya, serta keseharian dirinya. Hal tersebut menuai banyak respons dari khalayak yang dimiliki oleh Piko dalam akunnya, seperti follow, likes, comment serta repost (pengunggahan kembali) yang dilakukan oleh akun lain. Dari percakapan yang dilakukan bahwa dengan konten yang diunggah Piko ke dalam akunnya, beberapa galeri, serta event organizer, serta khalayak yang berkaitan dengan dunia seni rupa maupun khalayak biasa mulai mengikuti dirinya dalam akun Instagram@iabadioupiko.

Dengan ini penulis menganalisis bahwa relevansi yang dibangun dengan menggunakan personal branding yang dibentuk oleh Piko telah sesuai dengan followers atau khalayak yang dimilikinya. Karena khalayak menganggap bahwa konten yang dimiliki oleh Piko berhubungan dengan khalayak serta dianggap penting. Ditambahkan, menurut McNally dan Speak (2011), relevant adalah apa yang diwakili oleh merek tersebut berkaitan dengan apa yang dianggap penting oleh orang lain. Dengan adanya beberapa followers yang mengikuti akun Instagram @ iabadioupiko dirasa bahwa khalayak tersebut berkecimpung di dunia yang selaras dengan yang Piko tekuni. 
Penulis berpendapat bahwa khalayak menganggap akun@iabadioupiko termasuk ke dalam referensi mereka dan menganggap konten milik Piko penting bagi mereka, sehingga mereka mulai mengikuti dan menjadi salah satu followers dalam akun@iabadioupiko.

Visibilitas personal branding yang dibentuk harus disiarkan berkali-kali, terus-menerus, konsisten, dan berulang kali hingga tertanam di benak audiens (Rampersad, 2008). Dalam hal ini, menurut pengamatan penulis, akun Instagram @iabadioupiko telah memenuhi kriteria visibilitas. Hal ini terlihat dari konten Instagram @iabadioupiko yang selalu terpolakan dan selalu mengikuti kekonsistenan yang telah ditetapkan sebelumnya. Dalam setiap kegiatan yang dijalani oleh Piko pun, tidak lupa dirinya menggunggah konten foto kegiatan dirinya yang sedang maupun yang telah dijalaninya.

Persistence dalam membentuk dan membangun personal branding yang otentik membutuhkan suatu kegigihan dalam upayanya. Dari hasil penelitian, kegigihan@ibadioupiko dalam membentuk dan membangun personal branding yang dimilikinya sebagai seorang perupa sudah dimulai sejak lama. Dalam membangun personal branding, Piko tetap teguh untuk menjadi diri sendiri, apa adanya layaknya keseharian dirinya. Perihal mengatur konten yang akan diunggah ke dalam akun Instagramnya pun piko selalu teguh untuk memperhatikan bahwa konten yang diunggah harus memiliki value yang baik, baik untuk dirinya pribadi maupun untuk khalayak yang mengikutinya. Keprofesionalan Piko dalam bekerja sebagai seorang perupa, telah berpengalaman, dan telah banyak mengadakan pameran, baik dalam negeri maupun di luar negeri, dirasa penulis cukup untuk memenuhi karakteristik goodwill dalam membentuk personal branding yang otentik. Hal ini dapat dilihat dari terjadinya kerja sama dirinya dengan pihak galerigaleri yang terus berlanjut.

Karakteristik terakhir dalam membentuk personal branding yang otentik adalah performance (Rampersad, 2008). Dalam menjaga eksistensi Piko menjadi seorang perupa, Piko akan selalu menjaga interaksi yang terjadi dalam akunnya @ ibadioupiko dengan cara tetap mengunggah konten-konten pada akunnya. Hal ini dilakukan untuk tetap menjangkau khalayak yang dimilikinya agar akun @ibadioupiko terlihat sebagai sebuah akun yang selalu beraktivitas. Selanjutnya, untuk menjaga keseluruhan personal branding yang telah dibentuk, kunci dari segalanya adalah untuk tetap menjadi diri sendiri, yang dimaksud adalah tidak mengubah ataupun lari dari alur yang telah ditetapkan oleh Piko. Tetap menjalankan setiap unsur karakteristik yang ada guna menyempurnakan personal branding yang dibentuk. Ditambahkan, Piko tetap melakukan pengecekan terhadap akun Instagram yang dimilikinya, setiap unsur yang terdapat di Instagram-nya selalu diperhatikan. Interaksi kepada khalayak pun turut dipertimbangkan seperti baik-buruknya suatu komentar yang masuk pada akunnya, selalu dibalas dan 
disaring agar mendukung personal branding yang dibentuk dan dibangunnya pada akun@ ibadioupiko.

Berdasarkan analisis penulis terhadap data yang telah didapat melalui wawancara dengan informan serta pengamatan yang dilakukan dalam akun @ iabadioupiko, penerapan kesebelas karakteristik yang dilakukan oleh piko adalah berdasarkan ambisi pribadi yang selaras dengan keseharian pribadi, tidak membohongi pribadi dalam menciptakan personal branding. Sehingga terciptalah personal branding pribadi yang baik dan bertahan lama.

\section{KESIMPULAN}

Strategi personal branding oleh Piko sebagai perupa dengan akun Instagram @iabadioupiko, pada tahun 2020 ini di dalam akun Instagram-nya sudah ada sekitar 1,942 unggahan dengan 9,531 pengikut dan berisi foto-foto hasil karyanya ataupun potongan video proses dalam berkarya termasuk foto-foto dokumentasi saat pameran di dalam negeri maupun di luar negeri.

Secara keseluruhan akun Instagram @iabadioupiko sesuai dengan kesebelas karakteristik personal branding (authenticity, integrity, consistency, specialization, authority, distinctiveness, relevant, visibility, persistence, goodwill, performance). Authenticity: sebagai perupa berprestasi dan seorang yang simpel dan semangat. Integrity: memiliki konten yang teratur dan selalu positif, yaitu memilah dan melakukan penyaringan pada konten. Specialization: bidang lukis abstrak. Authority: pengakuan dari orang lain yang bekerja sama dengan Piko serta pengalaman yang dimilikinya. Relevant: yaitu banyaknya akun yang mengikutinya maupun yang memberikan respons pada konten Piko di Instagramnya. Visibility dan konsistensi terlihat dari seringnya Piko mengunggah kontennya serta selalu memiliki penggambaran yang serupa dan tertata sehingga semakin memperjelas dirinya pada khalayak. Terakhir, perencanaan konten, keteguhan Piko dalam konten unggahannya serta pandangan positif yang diraihnya menjadi poin dalam persistence, goodwill serta menjalin interaksi dengan tetap berdasarkan kesepuluh karakteristik sebelumnya sebagai kunci dalam performance. Personal branding yang telah dibentuk kemudian disatukan dengan media yang dimiliki, yaitu Instagram serta terdapatnya audiens yang menerima pesan personal branding yang ingin disampaikan, maka terciptalah personal brand di benak khalayak. Penelitian selanjutnya dapat dilakukan dengan menggunakan objek yang sama dengan subjek maupun platform yang berbeda agar lebih menggali penelitian tentang personal branding. 


\section{KEPUSTAKAAN}

Fernandes, A., \& Afonso, L. U. (2014). Joana Vasconcelos: Managing an Artist's Studio in the 21 st Century. International Journal of Arts Management, 17(1), 54.

Gitosudarmo, indriyo. (2001). Manajemen Strategis. Yogyakarta: BPFE Yogyakarta.

Harsono. (2010). Manajemen Pengantar. Yogyakarta: Sekolah Tinggi Ilmu Ekonomi YKPN.

Mc Nally \& Speak. (2011). Be your own brand: achieve more of what you want by being more of who you are. San Fransisco: BerretKoehler Publisher, Moleong.

Nugraha, A. R. (2017). Branding kota bandung di era smartcity. Jurnal Ilmu Komunikasi, Vol. 8 No. 1, 1-16.

Rakhmat, J. (2009). Metode Penelitian Komunikasi Dilengkapi Contoh Analisis Statistik. Bandung: Remaja Rosdakarya.

Rampersad, H. K. (2008). Authentic personal branding. Jakarta: PPM Publishing.

Setianti, Y. (2016). Pemanfaatan media sosial dalam implementasi model komunikasi kesehatan reproduksi remaja. Komunikatif: Jurnal Ilmiah Komunikasi, Vol. 5 No.1, 1-24. 